\title{
UPRAVLJANJE TERMODIMNOM KOMOROM
}

\section{CONTROL OF THERMOSMOKE CHAMBER}

\author{
Stanko P. STANKOV ${ }^{1)}$, Saša P. ARSIĆ(2), Nikola B. DANKOVIĆ ${ }^{1)}$, Zoran D. ICIĆ ${ }^{1)}$ \\ ${ }^{1)}$ Elektronski fakultet UniverzitetA u Nišu, Niš \\ ${ }^{2)}$ EPS Elektrodistribucija Prokuplje
}

U radu se razmatra automatsko upravljanje termodimnom komorom, koja je namenjena za termičku obradu (sušenje, kuvanje, prženje, pečenje) i dimljenje mesa, mesnih proizvoda, ribe, sira itd. Komora poseduje električne grejače za sušenje i grejače za generisanje pare, ventilator s frekvencijskom regulacijom za cirkulaciju vazduha, integrisane sisteme za generisanje dima i eliminaciju otpadnog dima, elektromagnetne ventile za pranje i klapne za regulaciju otvora dimovodnog kanala. Upravljačka logika je na bazi PLC - a. Prikazivanje i zadavanje karakterističnih veličina i parametara kao što su temperatura, vlažnost vazduha u komori, tekuća vrednost vlažnosti u jednoj ili dve tačke proizvoda koji se tretiraju u komori i strujanje vazduha, vrši se na operatorskom panelu. Na panelu se zadaju programi i mogu se videti statusi uređaja, koji omogućavaju funkcionalnost termodimne komore. Procedura upravljanja komorom odvija se aktiviranjem odgovarajućih receptura, koje su kreirane na osnovu iskustava i zahteva tehnologa, a rezultat toga je dobar kvalitet proizvoda.

Ključne reči: sušenje; dimljenje, temperatura; vlaga; upravljanje

The paper discusses the automatic control of thermo-smoke chamber, which is designed for thermal processing (drying, cooking, roasting, baking) and smoking meat, meat products, fish, cheese, etc. The chamber has electric heating elements for drying and generating the steam, the fan with a frequency control for the air circulation, integrated systems for the generation of smoke and elimination of waste smoke, solenoid valves for washing and valves for regulation of the opening of the smoke channel. Control logic is based on PLC. Display and adjustment of characteristic values and parameters, such as temperature, air humidity in the chamber, the current value of the humidity in one or two point of products to be treated in the chamber and the flow of air is performed in the operator's panel. Programs are assigned on the panel and you can see the device status, enabling functionality thermosmoke chamber. Control procedure of chamber takes place by activating the corresponding recipes, which are created based on the experiences and demands of technology and the result is a good quality of products.

Key words: drying; smoking; temperature; humidity; control

\section{Uvod}

Jedan od načina za dugotrajno čuvanje mesa i mesnih proizvoda je njihovo podvrgavanje procesu sušenja. Tokom ovog procesa se iz proizvoda odstranjuje veći deo vode putem isparavanja, čime se smanjuje vlažnost površine materijala i usled nastale razlike koncentracije voda difundira iz unutrašnjosti prema površini materijala. Umanjenje procenta vode zaustavlja ili značajno usporava mikrobiološke aktivnosti tako da se smanjuje mogućnost kvarenja proizvoda. Imajući u vidu da je raspodela temperature u materijalu koji se suši nejednolika, usled neadekvatnog sušenja često dolazi do deformacije i pucanja proizvoda [1]. U termodimnoj komori se proces sušenja odvija na principu konvekcije, pri čemu se određeni procenat toplote s radnog fluida prenosi na proizvod koji se suši. Radni fluid sušare je vlažan nezasićen vazduh zagrevan pomoću instaliranih električnih grejača. Za cirkulaciju fluida koristi se ventilator s frekvencijskom regulacijom. Ovaj fluid "prihvata" i odvodi deo vlage koja se oslobađa u procesu sušenja. U komori se osim sušenja može vršiti i kuvanje, prženje, pečenje i dimljenje svih vrsta mesa i mesnih delikatesa, zatim tretman ribe, sira i dr.

Ovlaživanjem vodom se postiže $92 \%$ relativne vlažnosti. Voda se raspršuje na grejne površine komore pomoću elektromagnetnih ventila s diznama, kada nastaje pretvaranje vode u paru. Ventilacija komore se vrši dovodom svežeg vazduha preko klapni u trajanju od 5 do $10 \mathrm{~min}$. i u tom periodu se isključuju grejači. Komora po zatvaranju vrata postaje hermetički zatvoren sistem. Proizvodi koji se tretiraju postavljaju se u kolica sa stalcima i ubacuju unutar komore. Za konkretan tretman postoji odgovarajući tip kolica. Na slici 1 je prikazana fotografija termodimne komore i dimogeneratora [2]. 


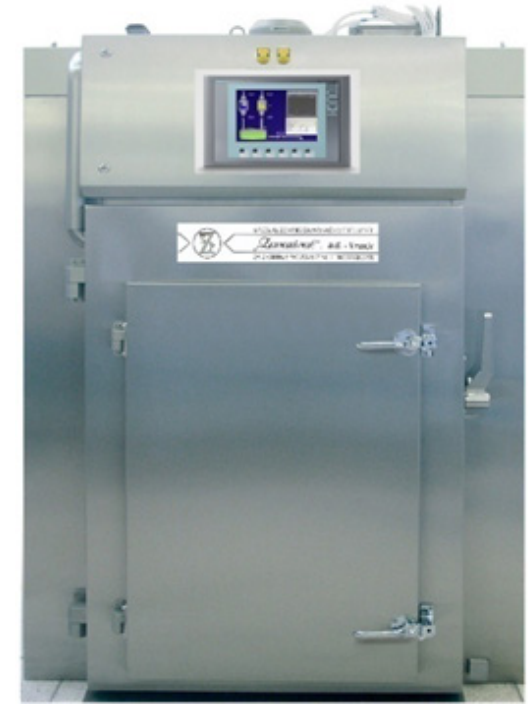

a) kompletna komora

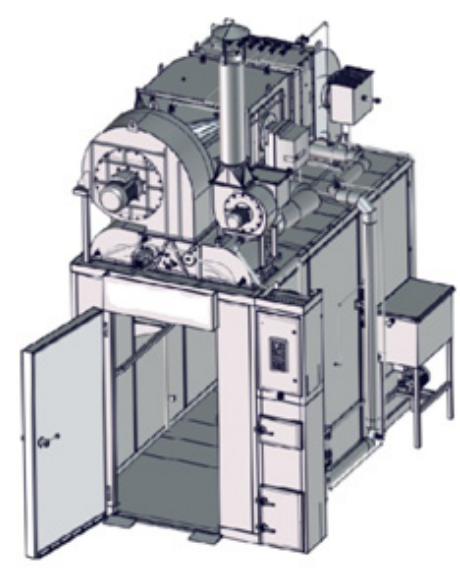

b) komora bez plašta

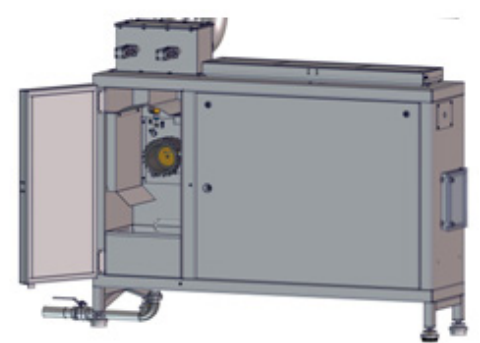

c) dimogenerator

Slika 1. Termodimna komora-proizvod firme SZP “Zavarivač” Vranje

Program pečenja se izvodi pomoću električnih grejača pri čemu su zatvorene klapne za dim i vazduh. Zadata vlažnost se postiže u roku od 10 do 15 min. (u zavisnosti od polazne temperature i vlažnosti). U frikcionom dimogeneratoru (slika 1c) čiji rad kontroliše upravljačka logika komore postoji mehanizam koji pritiska komad drveta na valjak za trenje, pri čemu se generiše dim koji se uvodi preko kanala u unutrašnjost komore. Ravnomernu raspodelu dima, temperature i vlažnosti, u svim delovima komore, omogućava ventilator s frekventno regulisanim brojem obrtaja. Sistem za provetravanje komore se sastoji od klapne za zatvaranje, dimnjačkog ventilatora i dimnjaka. Ugrađene klapne omogućavaju jednaku promenu količine vazduha koji struji s jedne na drugu stranu komore. Temperatura u komori se reguliše na osnovu merenja s dva Pt100 senzora (T1, T2), a temperatura unutar proizvoda se meri pomoću ubodne Pt100 sonde (Tp). Vlažnost se kontroliše na osnovu podataka sa senzora vlage (H1). U komori je ugrađen sistem automatskog pranja vodom preko elektromagnetnih ventila s diznama.

\section{Regulacija rada termodimne komore}

Temperaturni opseg u komori je od $40{ }^{\circ} \mathrm{C}$ do $200^{\circ} \mathrm{C}$, a vlažnost vazduha je u granicama od 0 do $92 \%$. Ambijent sušenja u komori je vazduh, a sušenje s dimljenjem se odvija pod uticajem hladnog ili vrućeg dima. Kuvanje se vrši pod dejstvom vodene pare, a pečenje vrše električni grejači.

Upravljačka jedinica termodimne komore je kontroler PLC Siemens S7 1200, koji je modularnog tipa. Jedinica S7 1200 ima mogućnost serijske komunikacije - protokoli RS - 232 i RS 485, korišćenjem dodatnih modula. Može se koristiti i MODBUS protokol (preko modula RS - 485) kao i USS protokol (Universal Serial Interface Protocol) za komunikaciju sa Simensovim frekvencijskim pretvaračima koji podržavaju ovaj protokol. Ova upravljačka jedinica ima i PROFINET priključak (jedna vrsta otvorenog Ethernet standarda) što joj omogućava povezivanje s drugim elementima automatizacije i sistemima koje podržavaju pomenuti protokol. Zahvaljujući ovome moguće je povezivanje više PLC - ova i operatorskih panela preko komunikacije koja se zasniva na ethernet i TCP/IP (Transport Control Protocol/Internet Protocol) protokolima [2].

Blok šema upravljačko - nadzornog sistema termodimne komore prikazana je na slici 2.

Termodimna komora se posmatra kao multivarijabilni sistem, gde je:

$\mathrm{r}^{\mathrm{T}}=\left[\mathrm{T}_{\mathrm{GSZ}}, \mathrm{T}_{\mathrm{GSZ}}, \mathrm{T}_{\mathrm{PGZ}}, \mathrm{T}_{1 Z}, \mathrm{~T}_{2 \mathrm{Z}}, \mathrm{T}_{\mathrm{PZ}}, \mathrm{T}_{\mathrm{DZ}}, \mathrm{H}_{1 \mathrm{Z}}\right]$ vektor ulaza - zadatih vrednosti, pri čemu dostizanje vrednosti $\mathrm{T}_{\mathrm{GSZ1}}$ (temperatura $\mathrm{u}$ grejnoj sekciji 1), $\mathrm{T}_{\mathrm{GSZ2}}$ (temperatura $\mathrm{u}$ grejnoj sekciji 2 ), $\mathrm{T}_{\mathrm{PG}}$ (temperatura proizvoda) izaziva nastajanje alarma (prekoračenja graničnih vrednosti temperature),

$\mathrm{e}^{\mathrm{T}}=\left[\mathrm{dT}_{\mathrm{GS} 1}, \mathrm{dT}_{\mathrm{GS} 2}, \mathrm{dT}_{\mathrm{PG}}, \pm \mathrm{dT}_{1}, \pm \mathrm{dT}_{2}, \pm \mathrm{dT}_{\mathrm{P}}, \pm \mathrm{dT}_{\mathrm{D}}, \pm \mathrm{dH}_{1}\right]$ vektor odstupanja (greški),

$\mathrm{y}^{\mathrm{T}}=\left[\mathrm{y}_{\mathrm{d} 1}, \mathrm{y}_{\mathrm{d} 2}, \mathrm{y}_{\mathrm{d} 3}, \mathrm{y}_{\mathrm{d} 4}, \mathrm{y}_{\mathrm{a} 1}, \mathrm{y}_{\mathrm{a} 2}, \mathrm{y}_{\mathrm{a} 3}, \mathrm{y}_{\mathrm{a} 4}, \mathrm{y}_{\mathrm{a} 5}, \mathrm{y}_{\mathrm{a} 5}\right]$ vektor izlaza,

$\mathrm{u}^{\mathrm{T}}=\left[\mathrm{DO}_{1}, \mathrm{DO}_{2}, \mathrm{DO}_{3}, \mathrm{DO}_{4}, \mathrm{DO}_{5}, \mathrm{DO}_{6}, \mathrm{AO}_{1}, \mathrm{AO}_{2}\right]$ vektor upravljanja [2]. 


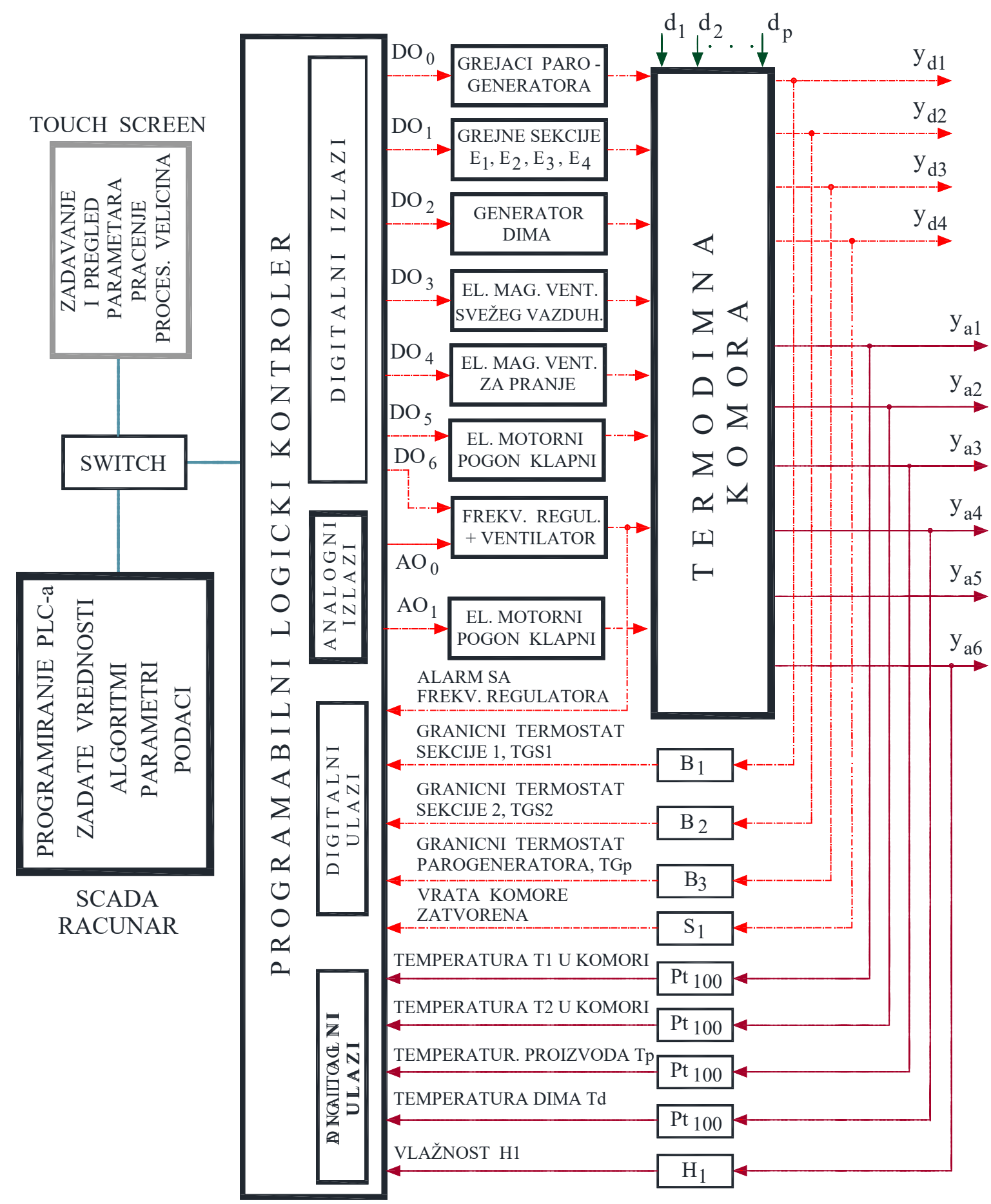

Slika 2. Blok šema upravljačko - nadzornog sistema termodimne komore

Konfiguracija i programiranje jedinice S7 1200 i razvoj nadzorno - upravljačkog programa za operatorski panel vrši se pomoću programske platforme TIA Portal (Totally integrated automation) koja ima int egrisan STEP 7 Basic za Siemens kontrolere i WINCC za vizuelizaciju preko Siemens operator panela. Koncipiranje upravljačke logike sa S7-1200 vrši se izborom i spajanjem različitih modula. Na centralnu procesorsku jedinicu (CPU) se, prema zahtevima procesa kojim se želi upravljati, dodaju različite vrste signalnih i komunikacijskih modula [3].

Procesor poseduje korisničku i sistemsku memoriju. Korisnička memorija se sastoji iz memorije za učitavanje (ROM - read only memory) - koja je neizbrisiva i radne memorije (RAM - random access memory), koja je izbrisiva - po nestanku napajanja brišu se podaci. Aplikativni program i 
parametri za konfiguraciju kontrolera unose se u ROM memoriju, koja je integrisana u centralnoj procesorskoj jedinici - CPU (central processing unit). Tokom prelaza procesora iz stanja STOP u stanje RUN, kopiraju se iz ROM - a u RAM programi i podaci potrebni za izvršavanje programa. U sklopu CPU jedinice je i sistemska memorija u kojoj se nalaze adrese promenljivih. Adresna područja memorije su: ulazi (I), izlazi (Q), bit memorijski prostor (M), prostor za blokove podataka (DB) i lokalna (privremena) memorija (L). Upravljački sistem se može povezati na SCADA računar na kome se vrši arhiviranje podataka [4 - 5].

Upravljački ormar sa instaliranim kontrolerom je prikazan na slici 3 .

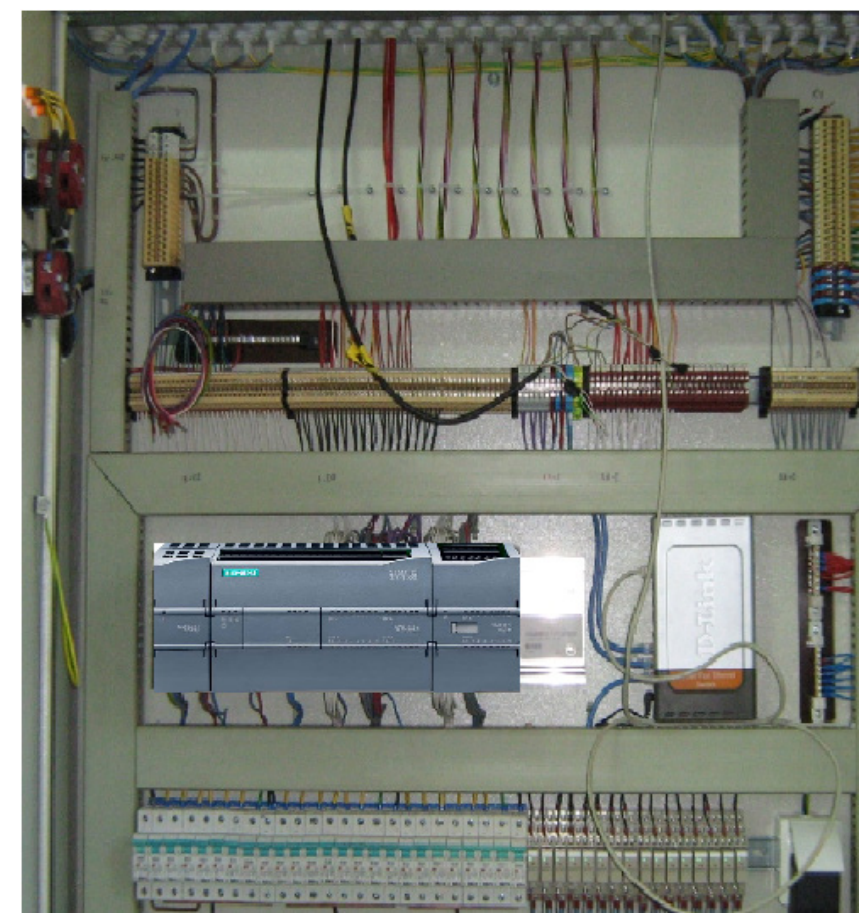

Slika 3. Upravljački ormar termodimne komore

\section{Interpretacija procesnih veličina}

Zadavanje i pregled parametara komore vrši se na operatorskom kolor panelu KTP600, koji u sprezi s PLC - om čini upravljačko - nadzorni sistem pod čijim su nadzorom senzori, prekidački elementi i izvršni organi (ventilatori, klapne, elektromagnetni ventili, električni grejači).

Na slici 4 je prikazan jedan ekran touch panela pri zadatoj recepturi koja omogućava kuvanje kobasica. Mogu se posmatrati zadate i tekuće vrednosti temperature i relativne vlažnosti u komori kao i vreme trajanja programa.

Jedan trend graf s prikazom zadatih i merenih vrednosti temperature i vlažnosti u komoru za vreme procedure sušenja mesa prikazan je na slici 5 . 

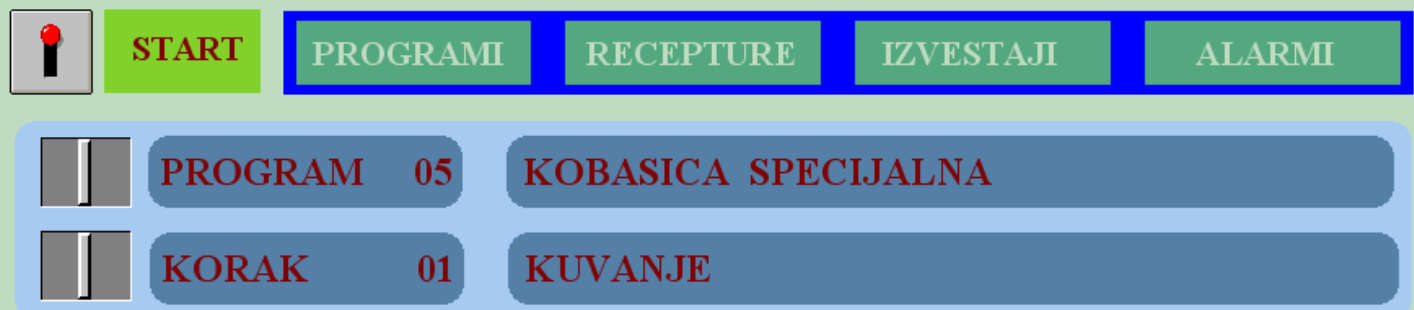

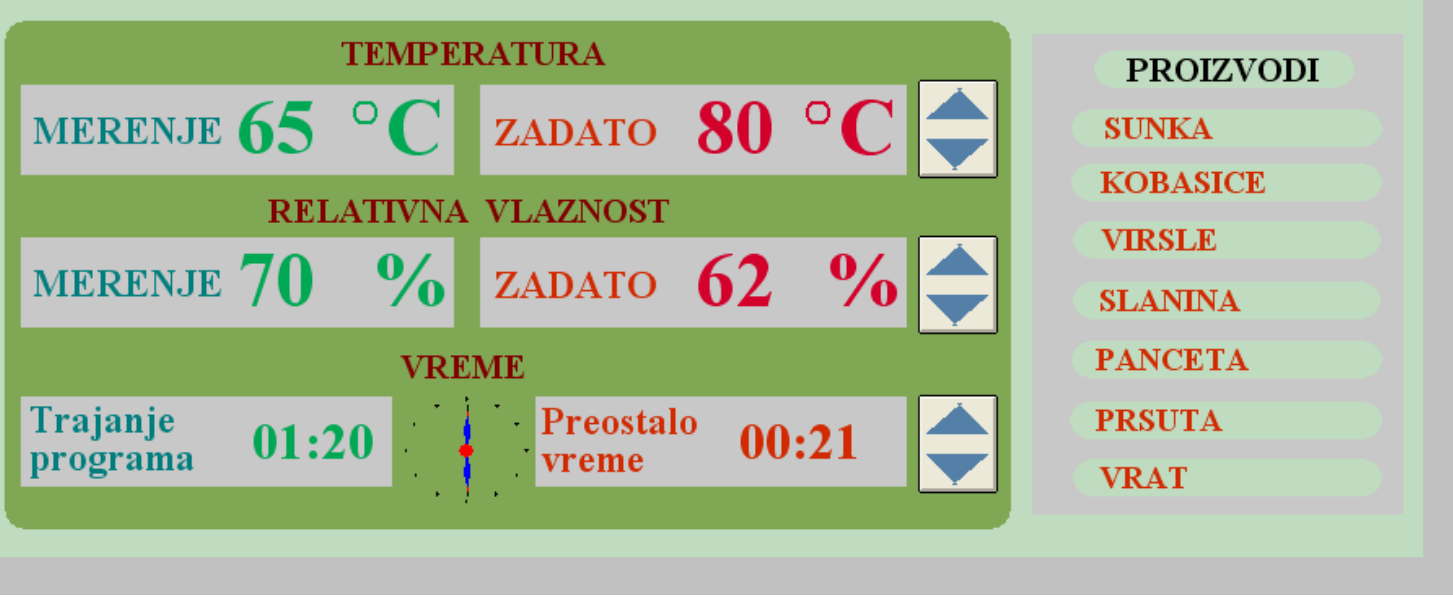

Slika 4. Ekran touch panela

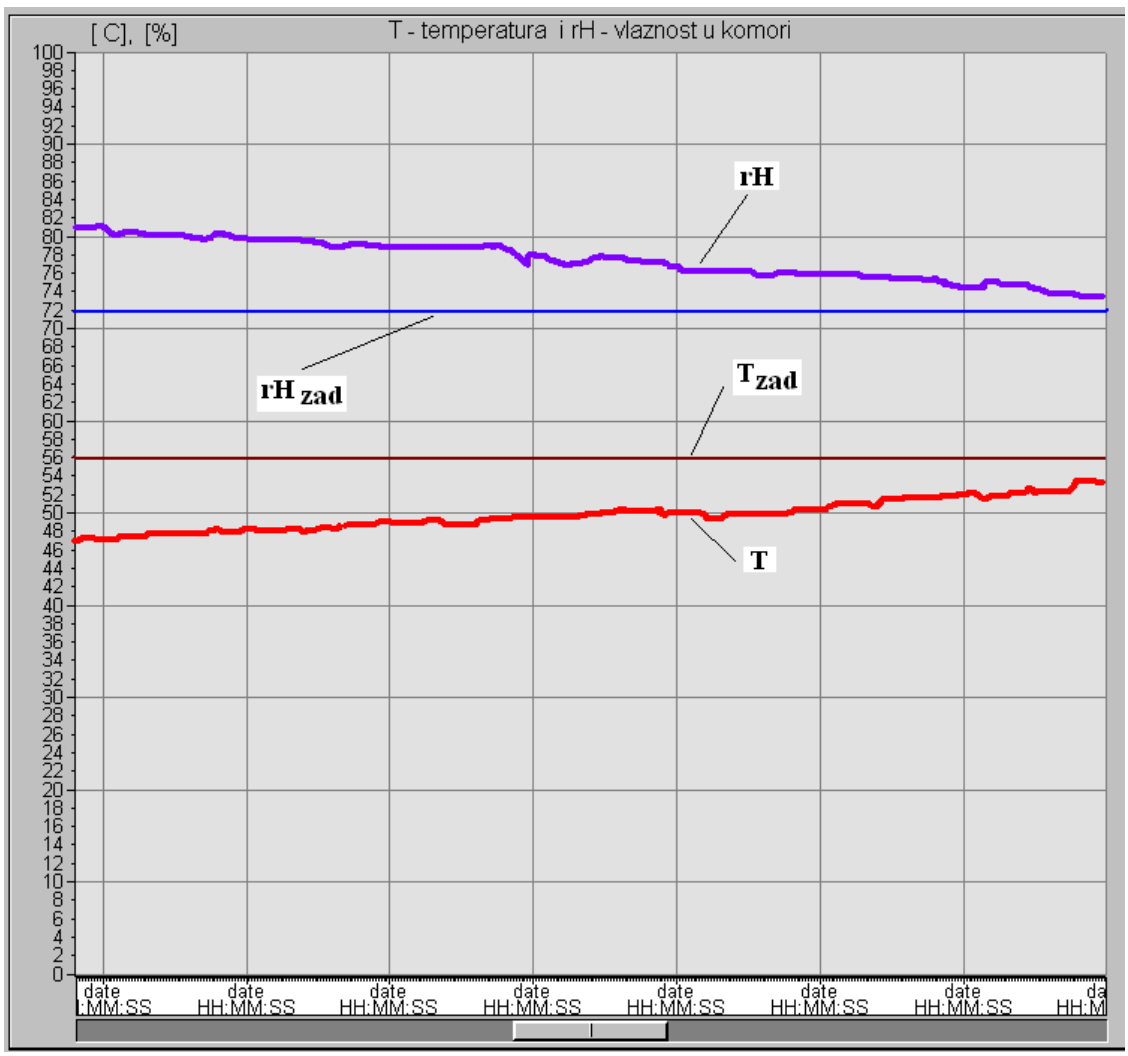

Slika 5. Dijagram temperature i vlažnosti termodimne komore u procesu sušenja mesa 


\section{$4 \quad$ Zaključak}

Prikazana termodimna komora sa integrisanim upravljačko - nadzornim sistemom omogućava:

- održavanje procesnih veličina (temperature i vlažnosti) na zadatim vrednostima,

- cirkulacija vazduha u komori ostvaruje se pomoću ventilatora s frekventnom regulacijom, što doprinosi smanjenju potrošnje električne energije, produžava se vek elektromotora i smanjuju električni udari u mreži,

- grafički prikaz procesnih veličina,

- prikaz alarma,

- arhiviranje podataka i generisanje izveštaja.

Ethernet mreža omogućava povezivanje PLC-a i komandnog touch panela s računarom i štampačem. Moguće je povezivanje preko ove mreže većeg broja termodimnih komora na centralni sistem nadzora i upravljanja.

\section{$5 \quad$ Literatura}

[1] Joksimović J., Z, Joksimović, Kvalitet i prerada mesa u domaćinstvu, Nolit, Beograd, 1983.

[2] Stankov S., Projekat automatskog upravljanja termodimnom komorom za sušenje mesa i mesnih proizvoda, ., SZP “Zavarivač” Vranje, Služba projektovanja Niš, 2004.

[3] Berger H., Automating with SIMATIC, 3rd revised edition, Publicis Corporate Publishing, Berlin and Munich, 2006.

[4] Malčić, G., D. Maršić, T. Lisak, Primjena PLC uređaja serije S7-1200 za upravljanje i vizualizaciju sustava odvodnje otpadnih voda, Tehničko veleučilište u Zagrebu, Elektrotehnički odjel, Zagreb, Hrvatska, 2011.

[5] Stankov, S., Primena kontrolera Siemens S7-1200 kod mašine za narezivanje zavrtnjeva, časopis Bakar, Volume 37, No. 1, str. $11 \div 22$, Izdavač:Institut za rudarstvo i metalurgiju, 2016. 